\title{
Inclusive path dependent analysis of sustainable urban environmental governance
}

\author{
M. H. Cheng \& J. W. Wu \\ National Sun Yat-sen University, Taiwan, ROC
}

\begin{abstract}
The government authorities generally intended to promote urban economic development by the execution of major public constructions, but the results of their decision-making system usually cause negative impacts or damage to the environment and non-sustainable abuse of the available resources.

Researchers criticized that the extractive institutions limit the operation of the decision system, while the inclusive decision institutions can lead to the formation of a virtuous cycle of economic and political systems.

This paper applies the theory of an inclusive path dependence history causal model, combined with the strategies of sustainable environmental governance, and application-oriented research methods, to examine the decision-making process of authorities in "Kaohsiung Asia's New Bay Area".

Because Kaohsiung city in Taiwan is now facing accelerated urbanization, economic degradation, climate change and extreme disasters, it is essential to find out the effective strategies required to solve the plight and problems. Finally, the results of this empirical study suggest that the government could deliver appropriate sustainable economic development and environmental governance policies, and use the information on positive feedback strategies with the system changes mechanism, to have the integrated effects of sustainable environmental governance.
\end{abstract}

Keywords: path dependence theory, inclusive institutions, environmental governance, Kaohsiung Asia's New Bay Area.

\section{Introduction}

Because the tendency of urbanization is global, the population of cities is much more concentrated than usual. But it also causes the serious problems of traffic 
chaos, energy consumption, air pollution, waste surge, and can lead to environmental negative impacts or cause serious environmental damage to cities.

While the cities governments generally still have to promote the urban economic development by the execution of major public constructions to provide the financial needs of people's lives. But the results of their decision-making system usually cause negative impacts or damage to the environment and nonsustainable abuse of the available resources.

Taiwan is an island in the Pacific Ocean, the natural resources of Taiwan is very shortage, and has to obtain the resources entirely by importations. And Kaohsiung city in Taiwan also is facing the accelerated urbanization, economic degradation and climate change extreme disasters now, so it is essential to find out the effective strategies to solve the above plight and problems.

Therefore, the governments are promoting the "Kaohsiung Asia's New Bay Area" in Kaohsiung city, expecting to conduct the major public constructions to facilitate and promote economic development.

However, the researchers Acemoglu and Robinson [1] stated that the extractive institutions limit the operation of decision system, while the inclusive decision institutions can lead to the formation of a virtuous cycle of economic and political system.

Thus, this paper applies the theory of an inclusive path dependence historical causal model, combined with the strategies of sustainable environmental governance, and the application-oriented research methods, to examine the decision-making process of authorities on "Kaohsiung Asia's New Bay Area".

Finally, the results of this empirical study suggest that the government could deliver appropriate sustainable economic development and environmental governance policies, and use the information positive feedback strategies with the system changes mechanism, to have the integrated effects of sustainable environmental governance.

\section{Research backgrounds}

Kaohsiung is a harbor city and is located in southern Taiwan. The city has to urgently face the serious problems of economic recession, so the governments need to much actively accelerate economic development. Therefore, the governments are conducting the major public construction of the "Kaohsiung Asia's New Bay Area" in Kaohsiung city to promote economic development.

The "Kaohsiung Asia's New Bay Area" construction plan [2] mainly contains four key public buildings and a Waterfront Light Rail Transit. The four key public buildings include: "Kaohsiung World Trade Exhibition and Convention Centre", "Kaohsiung Port and Cruise Service Center", "Kaohsiung Maritime Culture and Popular Music Center", and the "Kaohsiung Public Library".

The major public constructions in Taiwan are decided by the different decision makers of central and local governments. And the decision-making system to the major public constructions of the government agencies usually caused the relatively environmental negative impact or caused serious environmental damage. 
Furthermore, even the governments had spent a lot of effort to study the indicators of sustainable development strategies and actions, and they mostly still emphasized the technical recommendations for the improvements and recommendations for the environmental engineering and environmental programs, but focused less of their studies on institutional problems.

Because there are closely related issues among the urban major public constructions, a decision-making system, sustainable environmental management and urban development, economic activity, political conflicts, people's lives, and environmental protection, it is not easy to analyze and propose effective integration solutions, unless we derive the approach through the key elements path dependence of institutions.

Therefore, this research takes the "Kaohsiung Asia's New Bay Area" as an example, using the institutional economics and the path dependence theory to discuss the decision-making system for economic development and environmental governance issues, and recommends "positive information feedback" and a self-reinforcing mechanism to achieve sustainable environmental governance.

\section{Literature review}

According to previous results concerning the institutions research, in the human institutions exists the path dependent evolution system that decisions changes in the former stage will affect the relevant changes in the later stage. Then, the specification of institutions will be formatted by a virtuous circle or a vicious cycle of the institutions system. And the environmental sustainability governance system is also affected by this specification, therefore, the creation of incentives are very important in the first stage.

This paper reviews the relevant institutional research in the following sections.

\subsection{Path dependency theory}

North [3] proposed the path dependency theory in 1990, and stated that path dependence is the key to understanding the long-term economic change. And it has the positive feedback mechanism through the learning and coordination effects. Once the path had adopted, then it is hard to be changed, regardless the system is efficient or not, and the costs of changes are expensive.

Arthur [4] provided the empirical research of urban development system by the increasing returns of economics, positive feedback mechanism, path dependence, dynamic concepts and the historical research methods.

Scott [5] pointed out that the four factors of path dependence: increasing returns, self-reinforcement, positive feedback system and lock-in effect. Then Scott provided the dependent outcome-dependent process, equilibriumdependent process, Bernoulli process, dynamic processes theory and the other path dependent models.

Schreyögg [6] suggested the three phases in path dependence of the system and institutions, including the pre-formation phase, formation phase and lock-in 
phase. And Schreyögg also pointed out that the dynamic path dependency theory had been widely used in all kinds of fields, such as business studies, organizational development, economic history, political science, regional development fields.

Acemoglu and Robinson [1] stated that inclusive economic institutions are forged on the inclusive political institutions, which makes power broadly distributed in society. Inclusive economic institutions create a more equitable distribution of resources, and facilitate the persistence of inclusive political institutions.

\subsection{Institutional changes}

North [3] defined that institutions basically includes informal constraints (habits) and formal rules (laws), and the implementation features of the above both. While, the decision-making institutions of the governments are the key driving forces to the economic, political and environmental governance matters.

Hall [7] stated that Neo-institutionalism includes: rational choice institutionalism, sociological institutionalism and historical institutionalism. And the historical institutionalism could be used to study institutional changes and develop the core concept of "path dependence".

Gerhard [8] took the institutional changes of regional development program of Stuttgart city for example, and pointed out that although the industry is the core development of this city, but the city government still had to change institutions to upgrade the economic development globally and face the functional, cognitive, political lock-in limitations and establish its friendly innovative regional development system.

Mahoney [9] established the analytic structure approach of path dependence, including the antecedent historical, critical juncture, structural persistence, reactive sequence and final outcome.

\subsection{Comments}

Research on the path dependence theory is still developing, and the applications of this theory are diverse, including political, institutional, historical, economic, urban planning issues. But there is still little direct application in the sustainable urban environmental governance on major economic constructions.

Because the Kaohsiung city government urgently needs to improve the economic development and actively promote the major constructions of "Kaohsiung Asia's New Bay Area" by the city major public buildings to facilitate and promote economic development. But the sustainable governance to the urban environment still should be considered, and the path dependent institutional changes also should be examined.

Therefore, this study applies the path dependence theory as the main research manner, and combines with the ideas of dynamic decision-making institutional changes, and sustainable environmental management, to analyze the impacts of the major constructions of "Kaohsiung Asia's New Bay Area" plan. 


\section{Research design}

This paper basically applies the theory of inclusive path dependence historical causal model, Mahoney's analytic structure approach of path dependence, combined with the key concepts of sustainable environmental governance, and the application-oriented research methods, to examine the decision-making process of authorities on "Kaohsiung Asia's New Bay Area".

The basic assumption of this study includes: institutions shapes the decision path, and it is difficult to change the path, and the institution has a causal complexity. And the institutions change has a causal model due to the historical path dependency: the preferences and selection of decision-makers' $\rightarrow$ strategic interaction established by the decision-makers $\rightarrow$ the common path of environmental context and the institutional structure $\rightarrow$ path dependence $\rightarrow$ institutional changes.

This approach uses the historical stories axis system to analyze the historical development path of the Kaohsiung Harbor bay area, starting from the ancient fishing time, passed through the World War II, the Japanese occupation period to the present time.

There are many development plans induced on the harbor bay area, including the Asia-Pacific operations center constructions plan, the Asia-Pacific maritime operations heart plan, multi-trade zone plan, twelve love Taiwan construction plans, free trade plan, free trade port plan, Kaohsiung overall and future development plans, sea and air trade development program outline plan, and the present "Kaohsiung Asia's New Bay Area" plan.

As for this empirical study, the practical information mainly from the following references: governments' publications, development policies case studies, newspapers, public hearings, and website information. Then this paper uses the path dependency theory, academic decision-making system, and sustainable environmental governance to have the integrated policy analysis.

\section{Research results}

\subsection{Historical context}

Within this study, there is an evolution process and a historical context, while the current "Kaohsiung Asia's New Bay Area" concepts are put forward, so this research uses the historical dependent pathways causal model from "historical institutionalism" as follows.

\subsubsection{Decision preferences}

The government authorities generally intended to promote the urban economic development by the execution of major public constructions, but the results of their decision-making system usually cause negative impacts or damage to the environment and non-sustainable abuse of the available resources. 
Therefore, the central governments established many construction plans or projects in Kaohsiung city, and the "Kaohsiung Asia's New Bay Area" constructions plans are now underway, and there will be many more projects to be presented in the near future, such as the "Free Economic Pilot Zones" plan, which is the new national project for providing a friendly and supportive business environment.

\subsubsection{Strategic interaction}

In order to upgrade the development of Kaohsiung city effectively, all levels of government decision-makers (actors) are required to work together to build a more prosperous economic conditions to Kaohsiung city.

And the strategic interaction situations were coordinated by all the relevant interested parties and government decision-makers, including: the President, the Legislative Yuan, Executive Yuan, State agencies and other public utilities, and local Kaohsiung city government decision makers.

\subsubsection{Environmental context [2]}

Kaohsiung is located in the center of the Asia-Pacific region. The city has the unique features of mountain, sea, river, and port, and also possesses a rich culture and beautiful cityscape. Kaohsiung also is a harbor city, the Kaohsiung port is the world-class port in Taiwan as well as a hub for international trade. There are ceaseless ships and containers from around the world. And there are many heavy industrial production plants in this city, including steel, ships and fossil fuels manufacture plants.

Therefore, based on the analysis of the historical development approach, the governments have continued to induce many major development plans since 1930.

"Kaohsiung Asia's New Bay Area" plan comprises four major building projects and a new Waterfront Light Rail Transit. For example, the Kaohsiung Exhibition and Convention Center is constructed to promote international commerce and trade, it will host major international exhibitions and serve as an integrated marketing platform for the agriculture, IT, yacht, marine technology, automobile, metal fastener, electronics components, and tourism industries in southern Taiwan, and a propagator of exhibition-related industries.

\subsubsection{Path dependence}

This approach uses the historical stories axis system to analyze the historical development path of Kaohsiung harbor bay area, starting from the ancient fishing time to the present time. There are many development projects, including the Asia-Pacific operations center constructions plan, the Asia-Pacific maritime operations heart plan, multi-trade zone plan and Kaohsiung Asia's New Bay Area.

Although there is a process of path dependence along the above development plans, the "Kaohsiung Asia's New Bay Area" plan is attached to the "Kaohsiung Multifunctional trade zone specific area plan", and still has more complete and extended statutory regulations. 


\subsubsection{Institutional changes}

Furthermore, from the analysis of the cited detailed document, the original planning "Kaohsiung Multifunctional trade zone specific area plan" should still operate effectively. Both of the above plans are still unable to reach the required planning purposes and to play the effective function, therefore, they are still facing institutional change issues.

\subsection{Inclusive path dependence}

\subsubsection{Inclusive relationship}

Based on the above analysis, although the "Kaohsiung Asia's New Bay Area" plan is affiliated with the "Kaohsiung Multifunctional trade zone specific area plan", both plans have the path dependence causal relationship in the historical process.

The latter "Kaohsiung Asia's New Bay Area" plan came after the former "Kaohsiung Multifunctional trade zone specific area plan". While the former plan needs the latter plan to continue its institutional capabilities effectively.

Besides, the former plan is developed along the path dependence with the latter's relationship, and restricted the latter. Although the latter's functionality is subjected to the former plan continuously.

\subsubsection{System adjustment}

In order to perform the construction plan effectively, the government's decisionmakers should modify the strategic institutional function of the above plans using the information positive feedback mechanism and its self-reinforcing decision behaviors.

For example, according the 2014 year policy plan, the Kaohsiung city government is constructing the city to become a much more ecological, economic, livable, creative, international city, by upgrading and extending the development function of the above plans.

\subsection{Environmental governance}

According to the analysis of the historical path dependence process, the government authorities generally intended to promote the urban economic development by the execution of major public constructions, but the results of their decision-making system usually cause negative impacts or damage to the environment and non-sustainable abuse of the available resources.

In particular, there are too many constructions plans that have been introduced to the Kaohsiung bay area since 1930. Regards the "Kaohsiung Asia's New Bay Area", the constructions of "Kaohsiung World Trade Exhibition and Conference Centre" and the "Kaohsiung Public Library" had finished and are open to public. While the Waterfront Light Rail Transit, "Kaohsiung Ports and Harbors Travel Center" and "Maritime Cultural and Popular Music Center" are still under construction.

Therefore, before the approval of construction plans, the governments should inspect all the impact problems to the environment, consider the carrying 
capacities of the environment, and apply the environmental governance theories to examine the constructions plan systematically.

When the executers are constructing the plans, the governments should precisely control the progress, quality, environment protection, budgets, safety, and other relative social issues of all the construction works.

After the completion of all the constructions, the transportation and sightseeing services should achieve the constructions targets, and operational performance. While the security management, sustainable development, financial management should also should be well done.

According to the concepts of sustainable urban environmental governance, and takes the "Kaohsiung World Trade Exhibition and Conference Centre" as an example, the building should achieve the following functions: to strengthen the carbon reduction practices, have a good transportation parking management, control the disposal of waste and sewage, pay attention to sustainable operations management, pay attention to deal with the problem of rising sea levels, and improve the biodiversity protection capacities.

\subsection{Comprehensive analysis}

This paper provides the study of policy implications as follows:

The governments are facing the population concentrated urbanization, economic degradation, climate change and other issues of extreme disaster, therefore decision-making system should take into account the economic and environmental equity, management, and use "information positive feedback" and "system mechanism changes" and the self-reinforcing decision-making to achieve the overall aggregate effects.

The decision-making system of governments should take care of people's needs and actively upgrade economic development, and then still have to take the response to deal well with the global climate change issues and challenges. Finally the governments should systematically deliver the sustainable governance policies to the urban environment.

\section{Conclusion and further works}

\subsection{Conclusion}

Owing to global urbanization, the population of cities is too concentrated, and this induces serious environmental problems to cities. While the cities' governments usually promote urban economic development by the execution of major public constructions, they may cause negative impacts or damage to the environment.

Kaohsiung city in Taiwan is also facing accelerated urbanization and economic degradation issues. Besides, there are many constructions plans induced to the Kaohsiung harbor city, including the "Kaohsiung Multifunctional trade zone specific area plan" and "Kaohsiung Asia's New Bay Area" plan, which contain the four key public buildings: "Kaohsiung World Trade 
Exhibition and Convention Centre", "Kaohsiung Port and Cruise Service Center", "Kaohsiung Maritime Culture and Popular Music Center", and the "Kaohsiung Public Library".

This paper reviews the relevant path dependence research and empirical references, including the research of Acemoglu and Robinson's [1] inclusive economic institution and Mahoney's [9] analytic structure approach of path dependence.

This study then applies the theory of an inclusive path dependence historical causal model, combined with the key concepts of sustainable environmental governance, and the application-oriented research methods, to examine the decision-making process of government authorities on the "Kaohsiung Asia's New Bay Area" plan.

This paper concludes that there exists an evolution process and its historical context in the "Kaohsiung Asia's New Bay Area" plan, including the decision preferences, strategic interaction, environmental context, path dependence, and institutional changes. Finally, the comprehensive study suggests the decisionmaking mechanism of governments should systematically deliver the sustainable governance policies to the urban environment.

\subsection{Further works}

This paper examines the constructions historical path of "Kaohsiung Asia's New Bay Area" plan, and finds that there are too many hardware constructions that may have negative environment impacts on the city.

Therefore, this study suggests that the governments should deliver the sustainable economic development and environmental governance policies, and use the information positive inclusive feedback strategies with the system changes mechanism, to have the integrated effects of sustainable governance, and reach the overall aggregate synergy goals, then avoid the improper lock-in or negative exclusive feedback results.

Finally, this study proposes governments to deliver the sustainable economic development and environmental governance policies as follows:

1. Establish 2030 Kaohsiung conceived development vision (including the concepts of ecological city, livable city, green city, recycled city).

2. Develop the city with the green economy (renewable energy, and sustainable urban, transportation, and tourism).

3. Expand the innovation artistic cultural zone (including maritime pop music center, Railway Cultural Park).

4. Relocate the new Kaohsiung municipal center.

5. Integrate the harbor and the city competing functions, and strengthen the combined function of the Ports Corporation, Ltd. and the city government.

6. Develop the international passenger and cargo gallery, and enhance full portal functionality and activate the surrounding land use.

7. Review the overall plan of Kaohsiung Multifunctional trade zone specific area plan, to attract domestic and international investment, and to develop the shipping, logistics, flow, finance, business and high-tech international trade. 


\section{References}

[1] Acemoglu D. and Robinson J. A., Why Nations Fail: the origins of power, prosperity and poverty, Crown Publishers: New York, pp. 302-367, 2012.

[2] Kaohsiung City Government, http://urban-web.kcg.gov.tw/KDB/web_page/ KDB020100.jsp

[3] North, D. C., Institutions, institutional change, and economic performance, Cambridge University Press, pp. 112-117, 1990.

[4] Arthur, W. B., Increasing returns and path dependence in the economy, Ann Arbor: University of Michigan Press, 1993.

[5] Scott, E. P., Culture, Institutional Performance, and Path Dependence, Berkeley: Institute of Governmental Studies, University of California, 2006.

[6] Schreyögg, G. S. J, The Hidden Dynamics of Path Dependence Institutions and Organizations, Palgrave Macmillan: New York, pp. 4-8, 2010.

[7] Hall, P. R. T., Political Science and the Three New Institutionalism, Political Science, 45, pp. 936-957, 1996.

[8] Gerhard, F., Rethinking Regional Innovation and Change Path Dependency or Regional Breakthrough? Springer: New York, 2005.

[9] Mahoney, J., Path-Dependent Explanations of Regime Change: Central America in Comparative Perspective, Studies in Comparative International Development, 36(1), pp. 111-141, 2001. 